\title{
Disseminated Histoplasmosis in Persons with HIV/AIDS, Southern Brazil, 2010-2019
}

\author{
Rossana Patricia Basso, Vanice Rodrigues Poester, Jéssica Louise Benelli, \\ David A. Stevens, Melissa Orzechowski Xavier
}

We evaluated disseminated histoplasmosis (DH) in HIV patients over 10 years in southern Brazil. The incidence was 12 cases/1,000 hospitalizations (2010-2019); the mortality rate was $35 \%$. Tuberculosis frequently obscured the diagnosis of $\mathrm{DH}$. We emphasize the need in our region to suspect and investigate DH using more sensitive methods.

$\mathrm{D}$ isseminated histoplasmosis (DH) is an AIDSdefining disease and one of the major causes of death in persons living with HIV/AIDS (PLHIV) (mortality rate ranging from $13 \%$ to $48 \%$ ) (1-4). DH is a neglected disease because of its nonspecific symptoms, frequent misdiagnosis as tuberculosis (TB), and limited access to sensitive diagnostic methods $(3,5)$.

Worsening this scenario, an epidemic of AIDS is underway in Brazil; >800,000 new cases have been diagnosed in recent decades (6). Therefore, efforts are necessary to understand the epidemiology of $\mathrm{DH} /$ AIDS co-infection in the areas to which these diseases are endemic. We evaluated the clinical and epidemiologic profile of patients with DH/AIDS co-infection in a reference service for PLHIV over 10 years in southern Brazil and compared the incidence in periods before and after an internal hospital improvement of DH investigation.

\section{The Study}

We performed a retrospective study including all $\mathrm{DH}$ cases diagnosed in persons with HIV/AIDS at a

\footnotetext{
Author affiliations: Programa de Pós Graduação em Ciências da Saúde, Universidade Federal do Rio Grande, Rio Grande, Brazil (R.P. Basso, V.R. Poester, J.L. Benelli, M.O. Xavier); Hospital Universitário Dr. Miguel Riet Corrêa Jr., vinculado à Empresa Brasileira de Serviços Hospitalares, Rio Grande (R.P. Basso, J.L. Benelli); California Institute for Medical Research, San Jose, California, USA (D.A. Stevens); Stanford University Medical School, Stanford, California, USA (D.A. Stevens)
}

DOI: https://doi.org/10.3201/eid2803.212150 regional reference service in University Hospital Dr. Miguel Riet Corrêa Jr. (UH-FURG-Ebserh), a 207-bed tertiary hospital in Rio Grande, Brazil, that serves as reference center for 21 cities in Brazil. The hospital has an average of $257 \mathrm{HIV} /$ AIDS hospitalizations/ year (7). DH cases were defined by 1) classical methods: growth of $H$. capsulatum in culture, presence of blastoconidia suggestive of $H$. capsulatum by Gomori-Grocott stain (direct mycological examination or histopathology), or both; 2) serologic method: positive immunodiffusion test (IMMY, https://www. immy.com); or 3) urinary antigen test: positive immunoenzymatic assay (IMMY). Patients with clinical suspicion of $\mathrm{DH}$ and $\geq 1$ of these diagnostic criteria were included. The study was approved by our university ethics committee (CEP/FURG, approval no. 234/2018).

We analyzed databases from the hospital for clinical and epidemiologic evaluation. In cases in which HIV and AIDS were diagnosed simultaneously, DH was considered the AIDS-defining illness. We calculated the overall incidence rate of DH per 1,000 hospitalizations of persons with AIDS at UH-FURG-Ebserh (8); we then compared that with rates before improvement of $\mathrm{DH}$ investigation (2010-2016) and after improvement of DH investigation (2017-2019). These improvements consisted of health education and training of health professionals to improve clinical suspicion and implementing urinary antigen detection as another diagnostic method. Descriptive and frequencies analyses were performed in SPSS Statistics 25.0 (IBM, https:/ / www.ibm.com).

Our study included 31 cases of $\mathrm{DH}$, representing an overall incidence of 12 new cases/1,000 PLHIV hospitalized at UH-FURG-Ebserh. In the first period (2010-2016), 15 cases were diagnosed in 7 years, a rate of $8 / 1,000$ hospitalizations. After more sensitive testing and enhanced physician training were im- 
Table 1. Clinical-epidemiologic data of 31 disseminated histoplasmosis cases diagnosed in persons living with HIVIAIDS, University Hospital Dr. Miguel Riet Corrêa Jr., Rio Grande, Brazil, 2010-2019

\begin{tabular}{|c|c|}
\hline Variable & Frequency, \% (no./total no. participants) \\
\hline M & $74(21 / 31)$ \\
\hline $\mathrm{F}$ & $26(8 / 31)$ \\
\hline \multicolumn{2}{|l|}{ Signs and symptoms } \\
\hline Weight loss & $100(31 / 31)$ \\
\hline Fever $\left(>37.8^{\circ} \mathrm{C}\right)$ & $100(31 / 31)$ \\
\hline Respiratory: cough and/or dyspnea & $100(31 / 31)$ \\
\hline Cutaneous: papular and/or ulcerated & $52(16 / 31)$ \\
\hline Neurologic: disorientation, focal deficit, paresthesia, confusion, headache and/or & $52(16 / 31)$ \\
\hline \multicolumn{2}{|l|}{ hemiplegia } \\
\hline Digestive: abdominal distension and pain, diarrhea and/or nausea & $81(25 / 31)$ \\
\hline Hepatomegaly & $55(17 / 31)$ \\
\hline Splenomegaly & $81(25 / 31)$ \\
\hline Generalized lymph node enlargement & $35(11 / 31)$ \\
\hline \multicolumn{2}{|l|}{ Image exams } \\
\hline Interstitial lung pattern & $55(17 / 31)$ \\
\hline Reticulonodular lung pattern & $32(10 / 31)$ \\
\hline Pulmonary nodules & $6(2 / 31)$ \\
\hline Mediastinal lymphadenopathy & $26(8 / 31)$ \\
\hline \multicolumn{2}{|l|}{ Blood assays } \\
\hline Anemia & $100(31 / 31)$ \\
\hline Inflammatory marker* & $100(31 / 31)$ \\
\hline Liver damage marker† & $84(26 / 31)$ \\
\hline Tissue injury markerł & $87(27 / 31)$ \\
\hline Thrombocytopenia & $74(23 / 31)$ \\
\hline \multicolumn{2}{|l|}{ HIV assays } \\
\hline CD4+ lymphocytes $\leq 100 / \mathrm{mm}^{3}$ & $71(22 / 31)$ \\
\hline CD4+ lymphocytes $\leq 50 / \mathrm{mm}^{3}$ & $48(15 / 31)$ \\
\hline HIV Viral load $\geq 50,000$ copies & $90(26 / 29)$ \\
\hline \multicolumn{2}{|l|}{ First choice antifungal treatment } \\
\hline None & $3(1 / 31)$ \\
\hline Amphotericin B deoxycholate & $81(25 / 31)$ \\
\hline Itraconazole & $16(5 / 31)$ \\
\hline \multicolumn{2}{|l|}{ Outcome after 12 months } \\
\hline Alive & $65(20 / 31)$ \\
\hline Dead & $35(11 / 31)$ \\
\hline $\begin{array}{l}{ }^{*} \text { C-reactive protein increased. } \\
\text { †Alkaline phosphatase increased. } \\
\text { †Lactate dehydrogenase increased }\end{array}$ & \\
\hline
\end{tabular}

plemented, 16 cases were diagnosed in only 3 years (2017-2019), a rate of 24/1,000 hospitalizations, a substantial increase.

Most patients were men; mean age was 41 (range 21-61) years (Table 1). Except for 3, all had co-infections diagnosed concomitantly (Table 2). The use of

Table 2. Frequency of co-infections in 31 patients with disseminated histoplasmosis diagnosed in persons living with HIVIAIDS, University Hospital Dr. Miguel Riet Corrêa Jr., Rio Grande, Brazil, 2010-2019

\begin{tabular}{lc} 
Infectious disease & $\begin{array}{c}\text { Frequency, \% (no./total } \\
\text { no. participants) }\end{array}$ \\
\hline Oral candidiasis & $61(19 / 31)$ \\
Confirmed tuberculosis & $29(9 / 31)$ \\
Neurotoxoplasmosis & $29(9 / 31)$ \\
Pneumocystosis & $23(7 / 31)$ \\
Herpetic encephalitis & $3(1 / 31)$ \\
Herpes zoster & $3(1 / 31)$ \\
Syphilis & $3(1 / 31)$ \\
Medullary cytomegalovirus & $3(1 / 31)$ \\
Mycobacterium avium infection & $3(1 / 31)$ \\
Herpes simplex infection & $3(1 / 31)$ \\
Hepatitis C & $3(1 / 31)$ \\
\hline
\end{tabular}

antiretroviral therapy at time of $\mathrm{DH}$ diagnosis was irregular or nonexistent in $90 \%(\mathrm{n}=28)$ of patients. Only 4 had $>200$ cells $/ \mathrm{mm}^{3}$ of CD4+ lymphocytes (mean 109 cells $/ \mathrm{mm}^{3}$; range $7-752$ cells $/ \mathrm{mm}^{3}$ ). In 6 (19\%), DH was the AIDS-defining illness. A total of 3 persons had DH associated with a systemic inflammatory response syndrome.

Eight $(26 \%)$ DH patients were empirically treated for TB (9); no cases were confirmed by GeneXpert MTB/RIF (Cepheid, https:/ / www.cepheid.com). Up to 12 (mean 5) clinical samples/patient were submitted for TB investigations before suspicion of $\mathrm{DH}$.

DH was diagnosed through classical mycologic exams in $14(45 \%)$ patients, serologic tests in $9(29 \%)$ patients, and urinary antigen assay in $4(13 \%)$ patients. Four $(13 \%)$ patients had $\geq 2$ positive results by different methods (Figure). The diagnosis of histoplasmosis occurred after a mean of 10 (range 1-28) days from the beginning of hospitalization. This timing probably represents an underestimated delay, 
because several patients reported symptoms that could have led to a diagnostic workup before the illness progressed to a point at which hospitalization was required.

The treatment of choice for $81 \%$ of patients was intravenous amphotericin deoxycholate $(0.7-1 \mathrm{mg} /$ $\mathrm{kg} / \mathrm{d}$, to a maximum $50 \mathrm{mg} / \mathrm{d}$ ) for 14 days, followed by oral itraconazole (200 mg every $8 \mathrm{~h}$ for 3 days, then $200 \mathrm{mg}$ every $12 \mathrm{~h}$ ) for 12 months. A total of 5 $(16 \%)$ patients were treated only with itraconazole $(4$ with early diagnosis of $\mathrm{DH}$ and 1 with renal dysfunction). Twelve months after the $\mathrm{DH}$ diagnosis, $35 \%$ of the patients had died (Table 1); 1 died before laboratory confirmation, and 4 died within an average of 25 (range 0-62) days after diagnosis of DH. Three patients died after 5-6 months while being treated with itraconazole, and 3 had recurrence of the disease after 6,7 , or 12 months because of antifungal interruption, which resulted in death (Table 1).

\section{Conclusions}

DH causes severe clinical manifestations in PLHIV that can lead to death (10). Improved knowledge of the local epidemiology of $\mathrm{DH}$ and education of reference services for PLHIV are essential to reduce underdiagnosis and contribute to patient survival (11), especially in Rio Grande, a harbor city with the highest rate of HIV/ AIDS among cities in Brazil with $>100,000$ inhabitants (7).

$\mathrm{DH}$ was the AIDS-defining illness in $21 \%$ of the patients in this study. Other co-infections $(12,13)$ were noted. Respiratory signs, splenomegaly, and cutaneous lesions were more commonly described in our patients than in other studies, possibly because late diagnosis led to more severe extent of the disease $(12,13)$. The high rate of neurologic impairment in our patients can be attributed to their co-infections; in $69 \%(9 / 13)$ of patients, this impairment was ascribed to neurotoxoplasmosis or herpetic encephalitis. In addition, neurologic signs were detected in 5 other patients without an ascribed neuropathogenic condition, meriting additional investigations.

Many of our patients were exhaustively investigated for $\mathrm{TB}$, and $26 \%$ were empirically treated for TB despite negative results from the highly sensitive GeneXpert MTB/RIF assay (Cepheid). The long investigations for TB delayed the confirmation of the $\mathrm{DH}$ diagnosis despite descriptions of the concurrence of these 2 diseases (14). TB is a major opportunistic disease in PLHIV (15), evidenced by $29 \%$ of our DH patients with concomitant TB. Thus, the investigation of both diseases must occur simultaneously (12), and

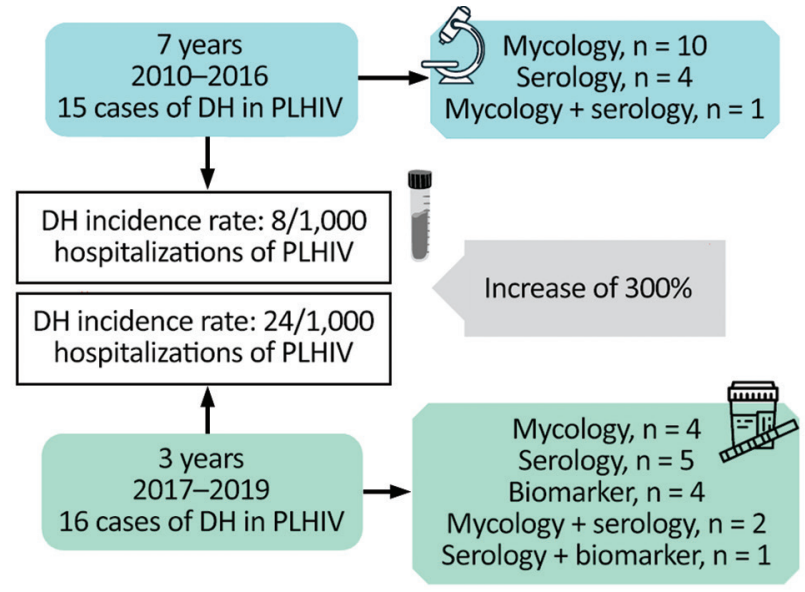

Figure. Approach used for the diagnosis of 31 cases of $\mathrm{DH}$ in PLHIV from a tertiary hospital in southern Brazil, 2010-2019. The incidence rate of $\mathrm{DH}$ between periods before (2010-2016) and after (2017-2019) implementation of the urinary antigen test shows an increase of $300 \%$. DH, disseminated histoplasmosis; PLHIV, persons living with HIV.

$\mathrm{DH}$ must be investigated in PLHIV with CD4+ lymphocytes $<200$ cells $/ \mathrm{mm}^{3}(11)$.

Tests to detect Histoplasma antibodies have poor sensitivity $(30 \%-70 \%)$ in immunocompromised patients (1). Diagnostic methods with high rates of sensitivity and specificity are vital in areas where histoplasmosis is endemic and could improve the likelihood of early diagnosis and favorable outcomes for patients $(1,12)$. An improvement in the investigation of DH in PLHIV with respiratory symptoms occurred in the UH-FURG-Ebserh in 2017, through a collaboration in a multicenter study (12). Subsequently, the results contributed to the acquisition of the urinary antigen assay by UH-FURG-Ebserh. In the last 3 years of our study, the urinary antigen test was the only method able to detect $25 \%(4 / 15)$ of our patients with $\mathrm{DH}$. The detection of urinary antigens is the standard for $\mathrm{DH}$ diagnosis in immunosuppressed patients (11).

The mortality rate in our series $(35 \%)$ was similar to the rate described in a systematic review from Brazil histoplasmosis cases (33\%) (10). Therefore, the underdiagnosis of DH in PLHIV is a national problem in Brazil that must be urgently changed. In our hospital, $\mathrm{DH}$ was responsible for high rates of illness in PLHIV, up to 24 cases/1,000 hospitalizations, and high mortality rates (35\%). In addition, we emphasize that $29 \%$ of patients were co-infected with TB, a disease with symptoms overlapping with histoplasmosis. Simultaneous investigation for the 2 diseases in all PLHIV patients living in areas in which histoplasmosis is endemic is mandatory. 


\section{Acknowledgments}

We thank Coordenação de Aperfeiçoamento de Pessoal de Nível Superior (CAPES) and Conselho Nacional de Desenvolvimento Científico e Tecnológico (CNPQ).

\section{About the Author}

Dr. Basso is a PhD physician working in infectious diseases. Her research field is in medical mycology, mostly concerning opportunistic fungal diseases in HIV patients.

\section{References}

1. Cáceres DH, Samayoa BE, Medina NG, Tobón AM, Guzmán BJ, Mercado D, et al. Multicenter validation of commercial antigenuria reagents to diagnose progressive disseminated histoplasmosis in people living with HIV/ AIDS in two Latin American countries. J Clin Microbiol. 2018;56:e01959-17. https://doi.org/10.1128/JCM.01959-17

2. Pasqualotto AC, Quieroz-Telles F. Histoplasmosis dethrones tuberculosis in Latin America. Lancet Infect Dis. 2018;18:1058-60. https:// doi.org/10.1016/S1473-3099(18) 30373-6

3. Centre d'Investigation Clinique Antilles Guyane C, Centre Hospitalier de Cayenne, Université de Guyane G. Disseminated histoplasmosis in Central and South America, the invisible elephant: the lethal blind spot of international health organizations. AIDS. 2016;30:167-70. https://doi.org/ 10.1097/QAD.0000000000000961

4. Samayoa B, Roy M, Cleveland AA, Medina N, Lau-Bonilla D, Scheel CM, et al. High mortality and coinfection in a prospective cohort of human immunodeficiency virus/acquired immune deficiency syndrome patients with histoplasmosis in Guatemala. Am J Trop Med Hyg. 2017;97:42-8. https:// doi.org/10.4269/ ajtmh.16-0009

5. Adenis AA, Valdes A, Cropet C, McCotter OZ, Derado G, Couppie P, et al. Burden of HIV-associated histoplasmosis compared with tuberculosis in Latin America: a modelling study. Lancet Infect Dis. 2018;18:1150-9. https:/ / doi.org/10.1016/S1473-3099(18)30354-2

6. Traebert J, Traebert E, Schuelter-Trevisol F, Cortez Escalante JJ, Schneider IJC. The burden of AIDS: a time series analysis of thirty-five years of the epidemic in Brazil. AIDS Care. 2018;30:1413-20. https://doi.org/10.1080/09540121.2018.14 56642

7. Ministry of Health, Brazil. National epidemiological bulletin HIV/AIDS, Brazil [in Portuguese]. 2020 [cited 2021 Oct 6]. https://www.gov.br/saude/pt-br/centrais-de-conteudo/ publicacoes/boletins/boletins-epidemiologicos/ especiais/2020/boletim-hiv_aids-2020-internet.pdf

8. Horta RL, da Costa JSD, Balbinot AD, Watte G, Teixeira VA, Poletto S. Hospitalizações psiquiátricas no Rio Grande do Sul de 2000 a 2011. Rev Bras Epidemiol. 2015;18:918-29. https://doi.org/10.1590/1980-5497201500040019

9. Ministry of Health, Brazil. Recommendations for TB-HIV co infection control in specialized facilities for people living with HIV [in Portuguese]. 2013 [cited 2021 Oct 6]. https://bvsms.saude.gov.br/bvs/publicacoes/ recomendacoes_manejo_coinfeccao_tb_hiv.pdf

10. Almeida MA, Almeida-Silva F, Guimarães AJ, Almeida-Paes R, Zancopé-Oliveira RM. The occurrence of histoplasmosis in Brazil: A systematic review. Int J Infect Dis. 2019;86:147-56. https://doi.org/10.1016/j.ijid.2019.07.009

11. Pan American Health Organization/World Health Organization. Guidelines for diagnosing and managing disseminated histoplasmosis among people living with HIV. 2020 Apr 1 [cited 2021 Oct 6]. https:/ / www.who.int/ publications/i/item/9789240006430

12. Falci DR, Monteiro AA, Braz Caurio CF, Magalhães TCO, Xavier MO, Basso RP, et al. Histoplasmosis, an underdiagnosed disease affecting people living with HIV/AIDS in Brazil: results of a multicenter prospective cohort study using both classical mycology tests and Histoplasma urine antigen detection. Open Forum Infect Dis. 2019;6:ofz073. https://doi.org/10.1093/ofid/ofz073

13. Nacher M, Valdes A, Adenis A, Blaizot R, Abboud P, Demar $\mathrm{M}$, et al. Disseminated histoplasmosis in HIV-infected patients: a description of 34 years of clinical and therapeutic practice. J Fungi (Basel). 2020;6:E164. https://doi.org/10.3390/jof6030164

14. Tucker RM, Hamilton JR, Stevens DA. Concurrent bloodstream infection with Histoplasma capsulatum and Mycobacterium tuberculosis. J Med Vet Mycol. 1991;29:343-5. https://doi.org/10.1080/02681219180000531

15. Boffo MMS, de Mattos IG, Ribeiro MO, Neto ICO. Tuberculosis associated to AIDS: demographic, clinical and laboratory characteristics of patients from a reference center in Southern Brazil [in Portuguese]. J Bras Pneumol. 2004;30:140-6. https://doi.org/10.1590/ S1806-37132004000200011

Address for correspondence: Melissa Orzechowski Xavier, Laboratório de Micologia, Faculdade de Medicina, Universidade Federal do Rio Grande, Campus Saúde. Visconde de Paranaguá 102, Centro, 96201-900, Rio Grande, RS, Brazil; email: melissaxavierfurg@gmail.com 